Portland State University

PDXScholar

$12-1-2021$

\title{
Do Loneliness and Social Isolation Predict Mortality Because of Hazardous Drinking?
}

Jussi Tanskanen

University of Jyväskylä

Sarah N. Arpin

Gonzaga University

Cynthia D. Mohr

Portland State University, cdmohr@pdx.edu

Follow this and additional works at: https://pdxscholar.library.pdx.edu/psy_fac

Part of the Psychology Commons

Let us know how access to this document benefits you.

\section{Citation Details}

Tanskanen, Jussi; Arpin, Sarah N.; and Mohr, Cynthia D., "Do Loneliness and Social Isolation Predict Mortality Because of Hazardous Drinking?" (2021). Psychology Faculty Publications and Presentations. 305.

https://pdxscholar.library.pdx.edu/psy_fac/305

This Post-Print is brought to you for free and open access. It has been accepted for inclusion in Psychology Faculty Publications and Presentations by an authorized administrator of PDXScholar. Please contact us if we can make this document more accessible: pdxscholar@pdx.edu. 
Do loneliness and social isolation predict mortality because of hazardous drinking?

Jussi Tanskanen (M.Soc.Sc.) Department of Social Sciences and Philosophy, University of Jyväskylä.

Sarah, Arpin (Dr), Department of Psychology, Gonzaga University, Spokane, WA, USA

Cynthia Mohr (Prof). Department of Psychology, Portland State University. Portland, OR, USA

Corresponding author: Sarah Arpin; email: arpin@gonzaga.edu; Tel: +1(509)313-6604, Add:

Department of Psychology, Gonzaga University, 502 East Boone Avenue, AD Box 054, Spokane, WA, 99204.

Acknowledgements: no conflict of interests.

This research was partly supported by the Kone Foundation. 


\begin{abstract}
Introduction: Subjective feelings of loneliness and objective social isolation have been consistently connected with ill-health and mortality, though previous studies are typically focused on older adults. Heavy alcohol consumption stemming from lack of social control has been suggested as a possible explanation for these adverse effects, though little work has empirically examined alcohol consumption as a mechanism for these effects. This study examines the relative and synergistic interaction effects of loneliness and social isolation on mortality in different age and gender groups, as a function of alcohol consumption.
\end{abstract}

Methods: The sample comprised a representative 1994 Finnish sample $(n=8650)$ matched with 22-year (1995-2016) follow-up register mortality data. A multigroup path analysis with discrete survival time analyses was conducted to examine whether alcohol consumption explained the connection of loneliness and social isolation to mortality in different age- and gender-defined groups.

Results: Loneliness and particularly social isolation predicted mortality partly through hazardous alcohol consumption for women under 40 and men 40-65. There was no synergistic interaction effect between loneliness and social isolation. Yet, there were unique differences in the associations between loneliness, social isolation, alcohol consumption and mortality based on age and gender groups.

Discussion: Loneliness and social isolation are associated with mortality, partly through subjective intoxication. Results highlight the importance of measuring mortality risk factors in younger adult populations. Interventions targeted at reducing loneliness and social isolation may help address underlying causes of excess alcohol consumption and mortality. Keywords: Loneliness; Social isolation; Mortality; Alcohol consumption; Health behavior 
Social connections are important for individuals and larger communities. They can provide sources of social support (Berkman et al., 2000), opportunities for companionship, sense of meaning, and belonging (Berkman et al., 2000; Cohen, 2004). Recent studies report major declines in social connectivity (e.g., McPherson et al., 2006) and heightened rates of loneliness and social isolation have been documented in the United States and elsewhere (Klinenberg, 2016), even prior to COVID-19. This phenomenon has been explained by societal changes including individualization and demographic changes (Klinenberg, 2012; McPherson et al., 2006). Landmark meta-analysis research has established strong links between social connection and mortality (Holt-Lunstad et al., 2010; 2015) demonstrating risks comparable to traditional health-related risk factors, including smoking and obesity (Holt-Lunstad et al., 2010; Pantell et al., 2013). Theoretically, social relationships influence health via three broad pathways: biological, psychological and behavioral (e.g., alcohol consumption, smoking; Berkman et al., 2000; Pietromonaco \& Collins, 2017). Evidence linking social connection with alcohol consumption, and alcohol consumption with mortality, suggests that drinking behavior could partly explain the link between social connection and mortality. The purpose of this study is to examine evidence of such a link in a prospective design using a representative sample of adults in Finland.

Decreased social connectivity has been associated with greater loneliness and social isolation. Loneliness is subjective, defined as the psychological pain of perceived deficits in the quality or quantity of social ties or lack of desired companionship (Peplau \& Perlman, 1979). Social isolation refers to the objective state of lacking social contacts, typically defined as having small social networks, infrequent social contacts, being unmarried or not cohabiting, and not participating in social or civic activities (e.g., Cornwell \& Waite, 2009). Though social isolation 
can lead to loneliness, previous research has demonstrated a low-to-moderate correlation $(r=.20$ - .30; e.g., Beller \& Wagner, 2018a; Coyle \& Dugan, 2012) between the two constructs indicating that one can be lonely while having strong social connections, whereas lack of connections often does not predict loneliness. Loneliness and social isolation primarily have been studied separately in studies of mortality. Yet given their association, research should consider the manner in which they uniquely contribute to health outcomes. This is important as previous research has reported mixed findings in which some work suggests that only social isolation is connected with mortality (Elovainio et al., 2017; Tanskanen \& Anttila, 2016), whereas other studies have found loneliness to also be a significant predictor (Beller \& Wagner, 2018b; Holwerda et al., 2012).

Including both relationship predictors allows us to consider the relative and combined or synergistic (i.e., interactive) effects of loneliness and isolation on health. The examination of synergistic effects reveals whether those who are at the same time socially isolated and lonely have excess risk for higher alcohol consumption or mortality compared to those who are only either isolated or lonely. Being isolated without being lonely can indicate voluntary isolation whereas those who are both socially isolated and lonely might be suffering from involuntary isolation. Of the few previous studies exploring the combined or synergistic effects of loneliness and social isolation on health, some have found significant interaction between the two constructs (e.g., Beller \& Wagner, 2018b; Holwerda et al., 2012), whereas others have not (e.g., Cornwell \& Waite, 2009; Steptoe et al., 2013). Our study will provide a further test of this relationship, particularly in the context of risk-related behavior.

Of additional interest is the potential role of alcohol consumption as a key behavioral mechanism by which social relationships affect health (Berkman et al., 2000). Although social 
connections can foster alcohol consumption in social settings, the socially isolated might not have the same access to health-relevant information as those who are more socially integrated. Further, individuals who are extremely socially isolated may lack social controls and support gained from social relationships for maintaining health-promoting behaviors (Berkman et al., 2000; Holt-Lunstad et al., 2015). Lack of social connections has been associated with frequent drinking (Elovainio et al., 2017) and heavy drinking (Hanson, 1994; Kharicha et al., 2007). However, abstainers have also reported greater social isolation (Greenfield et al., 2002). Further, previous work has shown that controlling for health behaviors including alcohol consumption attenuates the social isolation-mortality link by 33\% (Elovainio et al., 2017), thus providing support for alcohol consumption as a mechanism through which isolation relates to mortality.

The evidence for associations between loneliness and alcohol use is mixed, with research showing no relationship (Cacioppo, et al., 2002) or a negative relationship (Theeke, 2010). Still other research has shown that lonely persons report higher drinking frequency (Elovainio et al., 2017), but such drinking does not mediate loneliness-health associations (Christiansen et al., 2016). Differences across the literature may be explained by considering type of drinking behavior (e.g., typical frequency vs. hazardous consumption).

A number of studies support a J-Curve relationship between alcohol consumption and mortality, including in Finland, such that moderate drinkers show the lowest relative risk, whereas mortality increases with increasing levels of heavy drinking (Halme et al., 2010; Plunk et al., 2014). Although scholars debate the risk present in the abstaining group because of their heterogeneous nature and confounding factors such as illness that both prevents drinking and predicts mortality (Plunk et al., 2014; Stockwell et al., 2016), data are clearer about the relationship between heavy episodic or hazardous drinking patterns and mortality (Graff-Iversen 
et al., 2013; Halme et al., 2010; Plunk et al., 2014). However, the degree to which social isolation and loneliness relate to mortality through drinking is unclear. The current study addresses this gap by exploring the indirect effects of loneliness and social isolation on mortality via total frequency of alcohol consumption and frequency of subjective intoxication.

The extent of individual differences in these associations, such as age differences, is also uncertain. Most mortality studies have focused on older adults (e.g., >65). Some research, however, suggests potential age differences in these effects. The best evidence to date from the Holt-Lundstad et al. (2015) meta-analysis found that the mortality risk of loneliness and social isolation was stronger for those under 65 than those over 65. Further, for those with Alcohol Use Disorders (AUD), average life span in Finland is short, (47-53 for men, 50-58 for women), and mortality rate ratios are increasing over time for men and women aged 30-44 years (Westman et al., 2015). Similarly, Roerecke and Rehm (2013) reported that the relative risk is substantially higher for those 40 years of age and younger when considering AUD and all-cause mortality. Further, in their age-stratified analysis, Knott et al. (2015) revealed that dose-response relationships between protective low intensity alcohol consumption and all-cause mortality were largely limited to $65+$ year old women, whereas men enjoyed little protective effects of alcohol consumption. Thus, it would be beneficial for studies of mortality to include a broader age span and alcohol use indicators (beyond AUD) to detect the negative impacts of alcohol among young, as well as older adults.

In addition to age, there are well-documented gender differences in alcohol use crossculturally, with men drinking more often, at higher quantities, and more frequent hazardous drinking than women (Wilsnack et al., 2009). Conversely, there is little-to-no evidence for gender differences in the effects for loneliness and social isolation on mortality (e.g., Holt- 
Lunstad et al., 2015); where modest support is found, it suggests greater risk for men (Elovainio et al., 2017; Yang et al., 2013). Importantly, some work suggests that gender differences in drinking may be age specific (Bratberg et al., 2016). In their older adult (age >65) Finnish sample, Halme et al. (2010) documented a unique mortality risk for heavy-drinking men, though noting that heavy-drinking women were rare. Graff-Iversen et al. (2013) also found that heavy episodic drinking and all-cause mortality were related for men and women (aged 20-62). Yet Westman et al. (2015) documented significant increases in mortality risk ratios for men and women (aged 30-44) hospitalized with AUD, but more to a greater extent among women. In their meta-analysis of all-cause mortality, Roerecke and Rehm (2013) also reported higher mortality risks for women than men with AUD. Together, these results support the examination of potential gender differences by age group in social connection-mortality pathways through alcohol consumption.

\section{Current Study}

The current study builds on previous research to explore the relative and synergistic interaction effects of loneliness and social isolation on mortality. We also examine whether alcohol use, namely general consumption frequency and subjective intoxication frequency, serve as health behavioral mechanisms explaining associations among loneliness, isolation, and mortality. Lastly, we explore whether the role of alcohol differs among different gender and age groups via a multigroup analysis. Importantly, the current study controls for long-term illness which may hinder social relationships, impact drinking, and thus relate to mortality. Doing so helps to rule out reverse causality and potential selection effects (Holt-Lunstad et al., 2015) which may explain any demonstrated links among relationships, drinking, and mortality. 


\section{Methods}

\section{Sample and Procedure}

The study ( $\mathrm{n}=8650 ; 49.6 \%$ men) comprised a prospective, longitudinal design combining data from the Finnish Living Conditions Survey (FCLS; 1994) with a yearly, registry-based follow-up data set (1994-2016). The FLCS is a representative sample of uninstitutionalized (i.e. not living in rest home, hospital, prison) Finnish citizens with a high response rate of $73 \%$ (Ahola et al., 1995). The FLCS was collected by Statistics Finland through face-to-face interviews. Statistics Finland created the registry-based dataset via the social security numbers of survey respondents. The FLCS was matched with the follow-up registry data using id-numbers created by Statistics Finland. Average age in 1994 was $44.97(\mathrm{SD}=16.25$, range $=16-93)$.

\section{FCLS Measurements (Baseline)}

Loneliness was measured with a single-item measurement: "Do you ever feel lonely?" which has been validated against the well-established University of California, Los Angeles (UCLA) Loneliness Scale (Russell, 1996) and employed in health-related research (e.g., Pressman et al., 2005). Responses were recorded on a 5-point scale (1=never, 5=constantly). Previous research has defended the reliability of single-item assessments of moods (Myers \& Diener, 1995), interpersonal relationships (Fülöp et al., 2020), and loneliness (e.g., Bradburn, 1969; Lowenthal, Thurner, \& Chirboga, 1975). These single-item measures have the advantage of brevity (thus reducing participant fatigue on larger surveys) and high face validity (Larsen \& Fredrickson, 1999).

Social isolation was assessed via the multidimensional social isolation index. This index was based on the Berkman-Syme Social Network Index and parallels the scales utilized in previous studies (Pantell et al., 2013; Steptoe et al., 2013). The social isolation index reflected 4 
dimensions of isolation: (1) not living with a spouse, (2) isolation from family members, (3) isolation from friends, and (4) not participating in associational life (e.g., volunteer work, neighborhood activities). In total, social isolation dimensions were assigned with 13 items indicating specific type of isolations. The social isolation index was formed as a composite of the four dimensions and was scaled between 1 and 5 with higher values indicating greater isolation. As the social isolation index is a causal indicator measurement the measure of internal consistency is not meaningful (Diamantopoulos \& Winklhofer, 2001). Further, the social isolation index is based on social isolation theory and previous measures, which support the validity of the measure. In addition, the correlation between loneliness and social isolation was in line with previous studies offering validity to both measurements.

Frequency of overall alcohol consumption (FREQ; "How often do you consume alcohol? Try to include the times when you consume only a little amount of alcohol, for example a half a bottle of beer or a sip of wine") and subjective intoxication frequency (INTOX; "How often do you consume alcohol so that you can really feel its influence?") were assessed via an 11-point frequency scale (i.e., never to daily). Data were transformed to represent the number of drinking episodes per year. Previous research has validated single-item assessments of alcohol use, particularly for measures of drinking frequency and in screening for unhealthy alcohol use (e.g., Kim \& Hendershot, 2020; Viken, Rose, Morzorati, Christian, \& Li, 2003; Rehm et al., 1999). Confounding variables that might influence mortality and levels of loneliness and social isolation were adjusted in analyses. The baseline effects of age, educational level (basic, secondary, high), employment or student status, and having a long-term illness that hinders social interaction (to some extent or highly) were included in statistical models. 


\section{Registry-Based Data (Follow-up)}

All-cause mortality information was obtained from the registry follow-up data covering the years 1994 to 2016, which indicated whether participants had died at follow-up. A total of $1932(22 \%)$ respondents died in the follow-up period with average survival time of 11.99 years $(\mathrm{SD}=6.40)$.

\section{Statistical Analyses}

The indirect effect through alcohol consumption (FREQ and INTOX) was examined for the association of loneliness and social isolation on mortality. Relative and synergistic effects of loneliness and social isolation were examined with simultaneous analysis and by investigating the interaction effect. We tested the hypothesized path model for the mortality outcome via a discrete-time survival model (Muthén \& Masyn, 2005) in Mplus 8.0 (Muthén \& Muthén, 19982017). Respondents still alive after 2016 were modeled as censored observations. Associations and indirect effects were examined in six gender and age -defined groups (age was assessed at the 1994 assessment): (1) men under 40, (2) men between the ages of 40 and 65, (3) men over 65, (4) women under 40 years old, (5) women between the ages of 40 and 65, (6) women over 65. These age categories were chosen based on previous publications on this topic (e.g., HoltLunstad et al., 2015; Knott et al., 2015; Roerecke \& Rehm, 2013). Group differences in direct and indirect effects were examined with multigroup analysis via a mixture-model approach with known class option. Wald tests were performed to test the difference of estimates in different groups. Confidence intervals for the indirect and total effects were estimated with Monte Carlo simulations $(\mathrm{N}=100,000)$ utilizing $\mathrm{R}$ version 3.4 .3 software ( $\mathrm{R}$ Core Team, 2017) and the RMediation package (Tofighi \& MacKinnon, 2011). The number of missing observations was negligible $(<0.4 \%)$. Thus, listwise deletion of missing data was employed. 


\section{Results}

\section{Descriptive Statistics}

Descriptive analyses revealed differences in the age and gender groups for loneliness, social isolation and alcohol consumption (see Table 1). Correlations among main study variables in the overall sample are reported in Table 2. Overall, greater loneliness was related to greater INTOX, whereas greater social isolation was related to greater INTOX and less FREQ. Women under 40 and over 65 reported the highest levels of loneliness; men over 65 reported the lowest levels. Men and women above 65 were the most isolated. Across age groups, men consumed more alcohol than women; subjective intoxication frequency (INTOX) was more common for younger than older people. The median drinking frequency (FREQ) was a couple of times per month, whereas the median frequency of INTOX was 1-2 times per year. Mortality was greater among men than women in every age group. The correlation between loneliness and social isolation was similar across age groups, ranging from $r=.20-.23$, except for men over 65 ( $r=.31)$.

Other correlations among main study variables differed across age and gender groups, supporting the need for multigroup analyses.

A total of 1932 respondents died in the follow-up period of the study. Cardiovascular diseases $(\mathrm{N}=828,43.0 \%)$ and tumors $(\mathrm{N}=471,24.5 \%)$ were two most common causes of death. There were only few deaths caused by accidents and violence $(\mathrm{N}=115,6.0 \%)$ or directly alcohol related illnesses, accidents and poisoning $(\mathrm{N}=65,3,4 \%)$.

\section{Path Analyses}

Path model results are presented in Table 3 (coefficients and 95\% CI provided for the entire sample, i.e., all, and for gender-age groups). Analysis of the overall sample revealed (see Figure 1) that loneliness was significantly positively related to frequency of overall alcohol 
consumption (FREQ) and frequency of subjective intoxication (INTOX); lonelier participants reported greater frequency of overall consumption and subjective intoxication. Interestingly, social isolation was significantly associated with less FREQ, but increased INTOX. In turn, INTOX was positively connected with mortality, whereas the association of FREQ on mortality was zero. Loneliness and isolation also had significant direct effects on mortality. Interaction analysis revealed that the combined effect of loneliness and social isolation was not significant on mortality, FREQ or INTOX; the association of social isolation on mortality or alcohol use did not depend on level of loneliness.

The multigroup path model indicated that the connections among loneliness, social isolation, alcohol consumption and mortality were rather similar across different gender- and age-defined groups; interaction effects of loneliness and social isolation were nonsignificant in every group. Though some age and gender differences appeared large, the only statistically significant difference was for the associations of loneliness and social isolation on INTOX. Specifically, women under 40 exhibited a significant association between loneliness and FREQ greater loneliness was associated with greater overall frequency; this relationship was not significant for men under 40. The strongest association between loneliness and INTOX was among men 40-65. Loneliness was also significantly related to INTOX for women under 40, though not for women of other ages. Group comparisons revealed the association of loneliness on INTOX was significantly stronger for men 40-65 compared to men under 40 or women of any age. In addition, the relationship was significantly stronger for women under 40 compared to women over 65 .

Social isolation was generally associated with lower levels of FREQ particularly among men over 65. At the same time, social isolation was associated with higher levels of INTOX, 
particularly among men under 40, women under 40, and men between 40-65. The relationship was significantly stronger for men under 40 compared to other groups except women under 40. In addition, women over 65 had significantly weaker connection between isolation and INTOX than women under 40 or men 40-65. FREQ was not related to mortality, but INTOX significantly predicted mortality among men ages 40-65 and for women under 40. Loneliness significantly and directly predicted mortality among women under 40 and women ages 40-65. Social isolation was also significantly and directly related to mortality for men ages 40-65, women ages 40-65, and for women over 65 .

\section{Total and Indirect Effects}

Total and indirect effects of loneliness and social isolation through FREQ and INTOX on mortality are presented in the Table 4. In the whole sample, loneliness and social isolation had significant total effects on mortality. More specifically, loneliness predicted mortality significantly among women under 40 and women ages 40-65. Social isolation predicted mortality among men and women ages 40-65, and among women over 65 . Loneliness and social isolation did not have an indirect effect on mortality through FREQ. However, loneliness and social isolation indirectly predicted mortality via INTOX in the whole sample (i.e., across all age, gender groups). That is, greater loneliness and social isolation were associated with greater frequency of subjective intoxication (INTOX), which in turn predicted greater mortality; this pattern of results was only significant among women under 40 and men 40-65.

\section{Post hoc analyses by mortality type}

The associations of loneliness, social isolation, FREQ and INTOX on different mortality types were examined in post hoc analyses. Simple Cox-regressions adjusted with confounding variables revealed that loneliness was significantly connected with cancer mortality $(\mathrm{HR}=1.118$, 
95\% CI: 1.019-1.228), and social isolation predicted mortality caused by cardiovascular diseases (CVD) $(1.219,1.103-1.348)$, accidents and violence (including death by suicide; $1.756,1.367-$ 2.255), alcohol-related (1.444, 1.020-2.043) and other causes (1.463, 1.278-1.674). FREQ was associated with alcohol related mortality causes $(1.004,1.002-1.006)$ and INTOX with accidents (1.006, 1.002-1.011) and alcohol-related causes (1.007, 1.003-1.011).

\section{Discussion}

Consistent with previous work, loneliness and social isolation were adversely related to mortality across study participants, when studied simultaneously (i.e., Beller \& Wagner, 2018b; Holwerda et al., 2012). However, the direct effect of social isolation on mortality was remarkably stronger than that of loneliness, which is in line with the results of Elovainio et al. (2017) and Steptoe et al. (2013). In line with previous research (e.g., Cornwell \& Waite, 2009; Steptoe et al., 2013), there were no synergistic interaction effects between loneliness and social isolation on health as the interaction was nonsignificant in the whole sample and in every gender- and age-defined group. Loneliness did have a detrimental effect on mortality only among women under 65 , and especially women under 40 . Conversely, social isolation posed the greatest mortality risk for men aged 40-65 and women over 40 . Thus, contrary to previous research (Holt-Lunstad et al., 2015), there seemed to be some gender differences in isolation, loneliness, and mortality links, though these differences were mostly contingent on age group. Supporting the notions of Holt-Lunstad et al. (2015) the effects of loneliness and social isolation on mortality were in general stronger for younger people compared to those over 65 . This highlights the importance of examining alcohol-linked mortality risk factors among younger adult age groups. 
Associations among loneliness, isolation, and alcohol use revealed that, contrary to Cacioppo et al., (2002) and Theeke (2010), loneliness was related to greater frequencies of overall consumption and subjective intoxication. Interestingly, social isolation was associated with less frequent overall drinking, but greater frequency of subjective intoxication. This supports the notion that alcohol use has a social dimension; the socially isolated reported less overall consumption, which may be reflective of fewer opportunities to drink socially. But, on the other hand, isolation can also lead to heavy drinking (Hanson, 1994; Kharicha et al., 2007). Loneliness was associated with more frequent INTOX for older men and younger women, whereas social isolation was related to greater frequency of INTOX among younger men and women. The results reflect the change of Finnish alcohol culture in the younger generations, whereby the use of alcohol has equalized and is more socially acceptable for women. This finding also demonstrates the distinctiveness of social isolation and loneliness in predicting behavioral outcomes in different age groups.

Frequency of subjective intoxication, but not general alcohol consumption, predicted greater mortality risk across age- and gender-groups. Multigroup analysis revealed interesting differences within age- and gender-groups. Among men aged 40-65 and women under 40, INTOX was associated with greater mortality (Graff-Iversen et al., 2013; Roerecke \& Rehm, 2013); as such, INTOX partially explained associations of loneliness and social isolation with mortality. These effects of loneliness and isolation on alcohol use, alcohol use on mortality, and the overall indirect effects were partially contingent on gender and age. Overall, results supported our hypothesis that subjective intoxication is a health-damaging behavioral pathway connecting loneliness and social isolation with poorer health (i.e., mortality). 
Previous research has established that loneliness relates to health outcomes such as increased morbidity risk, poor cardiovascular health, diminished immune system functioning, and even the onset of dementia (e.g., Hawkley \& Cacioppo, 2010; Holwerda et al., 2012; Luo et al., 2012). Similarly, social isolation relates to overall health status (Hawton et al., 2011), depression (Leigh-Hunt et al., 2017) and multiple physical health issues, such as cardiovascular disease, coronary heart disease and stroke incidents (Leigh-Hunt et al., 2017; Valtorta et al., 2016). Our findings provide insight into why these connections may exist, in part, as a function of hazardous alcohol use. Further, we extend the findings of Herttua et al. (2011) beyond alcohol-related mortality to all-cause mortality, and examine indirect effects, thereby capturing a broader picture of mortality as linked to alcohol use.

Recommended strategies to reduce drinking, and thus mortality, include increased taxes and pricing of alcohol. Indeed, a meta-analysis of studies conducted in Finland showed a direct relationship between alcohol taxes and alcohol-related outcomes; these researchers argued that doubling taxes on alcohol would reduce alcohol-related mortality by an average of $35 \%$ more generally (Wagenaar et al., 2010). Westman et al. (2015) reported that in Finland, alcohol consumption peaked in 2002-2006 in direct relation to the alcohol tax reduction experienced during that time period. The current study findings suggest that while these approaches may help to decrease drinking and subsequently mortality, they do not address potential root causes of consumption, such as loneliness and social isolation. Focusing efforts and resources on interventions targeting perceived and objective social isolation would be beneficial, and likely have downstream effects on hazardous drinking and mortality. Interventions which increase opportunities for social contact among the socially isolated, and addressing maladaptive social 
cognitions for the lonely, may be valuable tools for public health approaches to consider (Masi et al., 2011).

\section{Study strengths and limitations}

The use of a large representative dataset with high response rate and few missing observations, combined with a prospective design, tests for indirect effects, and multigroup analysis, represent significant strengths of this study. Though loneliness, social isolation, and alcohol use were assessed cross-sectionally, the assessment of mortality over time via a registrybased follow-up remains a significant contribution of this study. Additionally, we examined the simultaneous effects of loneliness and social isolation, whereas research has mostly examined these constructs separately. Furthermore, the study adjusted for long-term illnesses that hinder social relationships to control for possible selection effects, wherein poor health would predict a lack of social relationships.

One main limitation of our prospective study design is that it is possible that levels of loneliness, social isolation and alcohol consumption changed during the follow-up period. Also, alcohol consumption was measured at the same time as loneliness and social isolation, making it impossible to determine their causal direction. Indeed, it is possible that sustained alcohol use may lead to social isolation and loneliness, to the extent that problematic use may damage social relationships and lead to poor relationship functioning (e.g., Crane, Testa, Derrick, \& Leonard, 2014). Yet, recent research examining the bidirectional effects between loneliness and riskrelated behavior (i.e., smoking, drinking) found no evidence of an effect of alcohol misuse on loneliness (Wootton et al., 2020). Moreover, substantive empirical and theoretical support exist for the direction of effects hypothesized in the current study (e.g., Arpin, Mohr, \& Brannan, 2015; Schonfeld \& Dupree, 1991; Gonzalez \& Skews. 2013). 
Further, although our own analyses revealed that overall alcohol consumption was not related to increased mortality (whereas frequency of INTOX was), we caution readers against drawing conclusions about health benefits of moderate consumption on mortality. Indeed, recent evidence has clearly shown that testing for health benefits of moderate consumption in population samples is fraught with challenges in that abstainers tend to be a heterogeneous group who abstain for a variety of reasons, including past alcohol-related problems (see Naimi et al., 2017; Zhao et al., 2017). We did not have data on alcohol use disorders (AUD), which may account for the mortality especially among younger participants in our sample (e.g., men $\leq 40$ years old are 9 times at greater risk of all-cause mortality when they had AUD, women $\leq 40$ years old 13 times more likely; Roerecke \& Rehm, 2013). Thus, we were not able to disentangle those who abstain but still may be at greater risk of mortality (e.g., those with lifetime alcohol use disorders).

Further, we were unable to control for confounds such as mental health status and comorbid disorders, which were not assessed on the FCLA. Similarly, we did not have information on quantity of consumption, which would provide interpretive context for the subjective intoxication reports. Evidence of individual differences (e.g., personality, family history of alcohol) or genetic heritability in subjective responses to alcohol has been documented (e.g., Viken, Rose, Morzorati, Christian \& Li, 2003); thus, respondents with similar reports of subjective intoxication are likely to be consuming different amounts of alcohol, with varying degrees of mortality risk associated with them. The alcohol use measurement in the 1994 survey represents a limitation relative to more contemporary measures; however, this limitation is substantially offset by the population representativeness of the survey sample and ability to predict comprehensive mortality records up to 22 years later. Lastly, although the current study 
reports some simple post hoc analyses on different types of mortality, the main analysis examined only all-cause mortality. Post hoc analyses suggested that loneliness was associated with cancer mortality and social isolation was related with CVD, accidents and violence, alcohol-related, and "other" type of mortality causes. However, these results are only preliminary as there were not enough cases in each mortality type to make meaningful comparisons or analyze associations in different age and gender groups. Additionally, cause of death as measured in the registry-based follow-up survey, was not specific enough to assess rates of death by suicide, which was included in the larger "accidents and violence" category. While the primary focus of the current study was to examine mortality risk more generally, suicide is indeed an important cause of death to consider, given known links between loneliness, isolation, and suicide mortality (e.g., Jeste, Lee, \& Cacioppo, 2020). Future work should consider how and whether loneliness and isolation predict distinct types of mortality (such as suicide), and whether these differences are explained by differences in alcohol consumption.

\section{Conclusion}

The current study employed a large, representative data set using longitudinal study design, along with the simultaneous examination of loneliness and social isolation effects on mortality to advance the current understanding of the combined impacts of loneliness and isolation on mortality as a function of alcohol use. The results of the study indicate that both loneliness and social isolation are connected directly with mortality and through more frequent hazardous alcohol consumption. Furthermore, the strength of the associations was more dependent on age than gender. Interventions targeted at reducing loneliness and social isolation should be implemented to address some of the root causes of excess alcohol consumption and mortality. 


\section{References}

Ahola, A., Djerf, K., Heiskanen, M., \& Vikki, K. (1995). Survey of Living Conditions 1994: Data Collection [in Finnish]. Helsinki, Finland: Living Conditions 2.

Arpin, S. N., Mohr, C. D, \& Brannan, D. (2015). Having friends and feeling lonely: A daily process examination of transient loneliness, drinking behavior, and the influence of interpersonal relationships. Personality and Social Psychology Bulletin, 41(5), 615-628. https://doi.org/10.1177/0146167215569722

Beller, J., \& Wagner, A. (2018a). Disentangling Loneliness: Differential Effects of Subjective Loneliness, Network Quality, Network Size, and Living Alone on Physical, Mental, and Cognitive Health. Journal of Aging and Health, 30(4), 521-539. https://doi.org/10.1177/0898264316685843

Beller, J., \& Wagner, A. (2018b). Loneliness, social isolation, their synergistic interaction, and mortality. Health Psychology, 37(9), 808-813. https://doi.org/10.1037/hea0000605

Berkman, L. F., Glass, T., Brissette, I., \& Seeman, T. E. (2000). From social integration to health: Durkheim in the new millennium. Social Science \& Medicine, 51, 843-857. https://doi.org/10.1016/S0277-9536(00)00065-4

Bradburn, N. (1969). The structure of psychological well-being. Chicago: Aldine.

Bratberg, G. H., Wilsnack, S. C., Wilsnack, R., Håvås Haugland, S., Krokstad, S., Sund, E. R., \& Bjørngaard, J. H. (2016). Gender differences and gender convergence in alcohol use over the past three decades (1984-2008), the HUNT Study, Norway. BMC Public Health, 16(1), 1-12. https://doi.org/10.1186/s12889-016-3384-3

Cacioppo, J. T., Hawkley, L. C., Crawford, L. E., Ernst, J. M., Burleson, M. H., Kowalewski, R. B., Malarkey, W. B., Van Cauter, E., \& Berntson, G. G. (2002). Loneliness and health: 
potential mechanisms. Psychosomatic Medicine, 64(8), 407-417.

Christiansen, J., Larsen, F. B., \& Lasgaard, M. (2016). Do stress, health behavior, and sleep mediate the association between loneliness and adverse health conditions among older people? Social Science and Medicine, 152, 80-86. doi.org/10.1016/j.socscimed.2016.01.020

Cohen, S. (2004). Social relationships and health. American Psychologist, 59, 676-684.

Cornwell, E. Y., \& Waite, L. J. (2009). Social disconnectedness, perceived isolation, and health among older adults. Journal of Health and Social Behavior, 50(1), 31-48. https://doi.org/10.1177/002214650905000103

Coyle, C. E., \& Dugan, E. (2012). Social isolation, loneliness and health among older adults. Journal of Aging and Health, 24(8), 1346-1363. https://doi.org/10.1177/0898264312460275

Crane, C. A., Testa, M., Derrick, J. L., \& Leonard, K. E. (2014). Daily associations among selfcontrol, heavy episodic drinking, and relationship functioning: An examination of actor and partner effects. Aggressive Behavior, 40(5), 440-450.

Diamantopoulos, A., \& Winklhofer, H. M. (2001). Index Construction with Formative Indicators: An Alternative to Scale Development. Journal of Marketing Research, 38(2), 269-277. https://doi.org/10.1509/jmkr.38.2.269.18845

Elovainio, M., Hakulinen, C., Pulkki-Råback, L., Virtanen, M., Josefsson, K., Jokela, M., Vahtera, J., \& Kivimäki, M. (2017). Contribution of risk factors to excess mortality in isolated and lonely individuals: an analysis of data from the UK Biobank cohort study. Lancet Public Health, 2(6), e260-e266. https://doi.org/10.1016/S2468-2667(17)30075-0

Fülöp, F., Bőthe, B., Gál, É., Cachia, J. Y. A., Demetrovics, Z., \& Orosz, G. (2020). A two-study validation of a single-item measure of relationship satisfaction: RAS-1. Current 


\section{Psychology, 1-13.}

Gonzalez, V. M., \& Skewes, M. C. (2013). Solitary heavy drinking, social relationships, and negative mood regulation in college drinkers. Addiction Research \& Theory, 21(4), 285294.

Graff-Iversen, S., Jansen, M. D., Hoff, D. A., Høiseth, G., Knudsen, G. P., Magnus, P., Mørland, J., Normann, P. T., Næss, O. E., \& Tambs, K. (2013). Divergent associations of drinking frequency and binge consumption of alcohol with mortality within the same cohort. Journal of Epidemiology and Community Health, 67(4), 350-357. https://doi.org/10.1136/jech2012-201564

Greenfield, T. K., Rehm, J., \& Rogers, J. D. (2002). Effects of depression and social integration on the relationship between alcohol consumption and all-cause mortality. Addiction, 97, 29-38.

Halme, J. T., Seppä, K., Alho, H., Poikolainen, K., Pirkola, S., \& Aalto, M. (2010). Alcohol consumption and all-cause mortality among elderly in Finland. Drug and Alcohol Dependence, 106(2-3), 212-218. https://doi.org/10.1016/j.drugalcdep.2009.08.017

Hanson, B. S. (1994). Social network, social support and heavy drinking in elderly men - a population study of men born in 1914, Malmö, Sweden. Addiction, 89(6), 725-732.

Hawkley, L. C., \& Cacioppo, J. T. (2010). Loneliness matters: A theoretical and empirical review of consequences and mechanisms. Annals of Behavioral Medicine, 40, 218-227. https://doi.org/10.1007/s12160-010-9210-8

Hawton, A., Green, C., Dickens, A. P., Richards, S. H., Taylor, R. S., Edwards, R., Greaves, C. J., \& Campbell, J. L. (2011). The impact of social isolation on the health status and healthrelated quality of life of older people. Quality of Life Research, 20(1), 57-67. https://doi.org/10.1007/s11136-010-9717-2 
Herttua, K., Martikainen, P., Vahtera, J., \& Kivimäki, M. (2011). Living alone and alcoholrelated mortality: A population-based cohort study from Finland. PLoS Medicine, 8(9). https://doi.org/10.1371/journal.pmed.1001094

Holt-Lunstad, J., Smith, T. B., Baker, M., Harris, T., \& Stephenson, D. (2015). Loneliness and Social Isolation as Risk Factors for Mortality A Meta-Analytic Review. Perspectives on Psychological Science, 10(2), 227-237. https://doi.org/10.1177/1745691614568352

Holt-Lunstad, J., Smith, T. B., \& Layton, J. B. (2010). Social relationships and mortality risk: A meta-analytic review. PLoS Medicine, 7(7). https://doi.org/10.1371/journal.pmed.1000316

Holwerda, T. J., Beekman, A. T. F., Deeg, D. J. H., Stek, M. L., van Tilburg, T. G., Visser, P. J., Schmand, B., Jonker, C., \& Schoevers, R. A. (2012). Increased risk of mortality associated with social isolation in older men: only when feeling lonely? Results from the Amsterdam Study of the Elderly (AMSTEL). Psychological Medicine, 42, 843-853. https://doi.org/10.1017/S0033291711001772

Jeste, D. V., Lee, E. E., \& Cacioppo, S. (2020). Battling the modern behavioral epidemic of loneliness: suggestions for research and interventions. JAMA psychiatry, 77(6), 553-554.

Kharicha, K., Iliffe, S., Harari, D., Swift, C., Gillmann, G., \& Stuck, A. E. (2007). Health risk appraisal in older people 1: are older people living alone an ' at-risk' group ? British Journal of General Practice, 57, 271-276.

Kim, J., \& Hendershot, C. S. (2020). A review of performance indicators of single-item alcohol screening questions in clinical and population settings. Journal of substance abuse treatment, 111, 73-85.

Klinenberg, E. (2012). Going solo. The extraordinary rise and surprising appeal of living alone. New York: Penguin Press. 
Klinenberg, E. (2016). Social Isolation, Loneliness, and Living Alone: Identifying the Risks for Public Health. American Journal of Political Science, 106(5), 786-787. https://doi.org/10.2105/AJPH.2016.303166

Knott, C. S., Coombs, N., Stamatakis, E., \& Biddulph, J. P. (2015). All cause mortality and the case for age specific alcohol consumption guidelines: Pooled analyses of up to 10 population based cohorts. BMJ, 350(h384). https://doi.org/10.1136/bmj.h384

Larsen, R. J., \& Fredrickson, B. L. (1999). Measurement issues in emotion research. In D. Kahneman, E. Diener, \& N. Schwarz (Eds.), Well-being: The foundations of hedonic psychology (pp. 40-60). New York, NY: Russell Sage.

Leigh-Hunt, N., Bagguley, D., Bash, K., Turner, V., Turnbull, S., Valtorta, N., \& Caan, W. (2017). An overview of systematic reviews on the public health consequences of social isolation and loneliness. Public Health, 152, 157-171. https://doi.org/10.1016/j.puhe.2017.07.035

Lowenthal, M. F., Thurnher, M., \& Chiriboga, D. A. (1975). Four stages of life. Jossey-Bass. Luo, Y., Hawkley, L. C., Waite, L. J., \& Cacioppo, J. T. (2012). Loneliness, health, and mortality in old age: A national longitudinal study. Social Science \& Medicine, 74(6), 907914. https://doi.org/10.1016/j.socscimed.2011.11.028

Masi, C. M., Chen, H.-Y., Hawkley, L. C., \& Cacioppo, J. T. (2011). A Meta-Analysis of Interventions to Reduce Loneliness. Personality and Social Psychology Review, 15(3), 219266. https://doi.org/10.1177/1088868310377394

McPherson, M., Smith-Lovin, L., \& Brashears, M. E. (2006). Social Isolation in America: Changes in Core Discussion Networks over Two Decades. American Sociological Review, 71, 353-375. https://doi.org/10.1177/000312240607100301

Muthén, B. O., \& Masyn, K. (2005). Discrete-Time Survival Mixture Analysis. Journal of 
Educational and Behavioral Statistics, 30(1), 27-58. doi.org/10.3102/10769986030001027

Muthén, L. K., \& Muthén, B. O. (1998-2017). Mplus User’s Guide. Eighth Edition. https://doi.org/10.1111/j.1600-0447.2011.01711.x

Myers, D. G., \& Diener, E. (1995). Who is happy? Psychological Science, 6, 10-19.

Naimi, T. S., Stockwell, T., Zhao, J., Xuan, Z., Dangardt, F., Saitz, R., Liang, W., \& Chikritzhs, T. (2017). Selection biases in observational studies affect associations between 'moderate' alcohol consumption and mortality. Addiction, 112(2), 207-214. https://doi.org/10.1111/add.13451

Pantell, M., Rehkopf, D., Jutte, D., Syme, S. L., Balmes, J., \& Adler, N. (2013). Social isolation: A predictor of mortality comparable to traditional clinical risk factors. American Journal of Public Health, 103(11), 2056-2062. https://doi.org/10.2105/AJPH.2013.301261

Peplau, L. A., \& Perlman, D. (1979). Blueprint for a social psychological theory of loneliness. In M. Cook \& G. Wilson (Eds.), Love and attraction: An international conference (pp. 101110). Oxford, England: Pergamon Press.

Pietromonaco, P. R., \& Collins, N. L. (2017). Interpersonal Mechanisms Linking Close Relationships to Health. The American Psychologist, 72(6), 531-542. https://doi.org/10.1109/EMBC.2016.7590696.Upper

Plunk, A. D., Syed-Mohammed, H., Cavazos-Rehg, P., Bierut, L. J., \& Grucza, R. A. (2014). Alcohol Consumption, Heavy Drinking, and Mortality: Rethinking the J-Shaped Curve. Alcoholism: Clinical and Experimental Research, 38(2), 471-478. https://doi.org/10.1111/acer.12250

Rehm, J, Greenfield, T.K., Walsh, G., Xie, X., Robson, L. \& Single, E. (1999). Assessment methods for alcohol consumption, prevalence of high-risk drinking and harm: A sensitivity 
analysis. International Journal of Epidemiology, 24, 929-936.

Roerecke, M., \& Rehm, J. (2013). Alcohol use disorders and mortality: A systematic review and meta-analysis. Addiction, 108(9), 1562-1578. https://doi.org/10.1111/add.12231

Russell, D. W. (1996). Russell - 1996 - UCLA Loneliness Scale (Version 3) Reliability, Validity, and Factor Structure. Journal of Personality Assessment, 66(1), 20-40.

Schonfeld, L., \& Dupree, L. W. (1991). Antecedents of drinking for early-and late-onset elderly alcohol abusers. Journal of Studies on Alcohol, 52(6), 587-592.

Steptoe, A., Shankar, A., Demakakos, P., \& Wardle, J. (2013). Social isolation, loneliness, and allcause mortality in older men and women. Proceedings of the National Academy of Sciences of the United States of America, 110(15), 5797-5801. doi.org/10.1073/pnas.1219686110

Stockwell, T., Zhao, J., Panwar, S., Roemer, A., Naimi, T., \& Chikritzhs, T. (2016). Do "Moderate” Drinkers Have Reduced Mortality Risk? A Systematic Review and MetaAnalysis of Alcohol Consumption and All-Cause Mortality. Journal of Studies on Alcohol and Drugs, 77(2), 185-198. https://doi.org/10.15288/jsad.2016.77.185

Tanskanen, J., \& Anttila, T. (2016). A prospective study of social isolation, loneliness, and mortality in Finland. American Journal of Public Health, 106(11), 2042-2048. https://doi.org/10.2105/AJPH.2016.303431

Team, R. C. (2017). R: A Language and Environment for Statistical Computing. Retrieved from http://www.r-project.org/

Theeke, L. A. (2010). Sociodemographic and health-related risks for loneliness and outcome differences by loneliness status in a sample of U.S. older adults. Research in Gerontological Nursing, 3(October), 113-125. https://doi.org/10.3928/19404921-20091103-99

Tofighi, D., \& MacKinnon, D. P. (2011). RMediation: An R package for mediation analysis 
confidence intervals. Behavior Research Methods, 43(3), 692-700.

https://doi.org/10.3758/s13428-011-0076-X

Valtorta, N. K., Kanaan, M., Gilbody, S., Ronzi, S., \& Hanratty, B. (2016). Loneliness and social isolation as risk factors for coronary heart disease and stroke : systematic review and metaanalysis of longitudinal observational studies. Hearth, 102, 1009-1016. https://doi.org/10.1136/heartjnl-2015-308790

Viken, R. J., Rose, R. J., Morzorati, S. L., Christian, J. C., \& Li, T. K. (2003). Subjective intoxication in response to alcohol challenge: heritability and covariation with personality, breath alcohol level, and drinking history. Alcoholism: Clinical and Experimental Research, 27(5), 795-803.

Wagenaar, A. C., Tobler, A. L., \& Komro, K. A. (2010). Effects of alcohol tax and price policies on morbidity and mortality: A systematic review. American Journal of Public Health, 100(11), 2270-2278. https://doi.org/10.2105/AJPH.2009.186007

Westman, J., Wahlbeck, K., Laursen, T. M., Gissler, M., Nordentoft, M., Hällgren, J., Arffman, M., \& Ösby, U. (2015). Mortality and life expectancy of people with alcohol use disorder in Denmark, Finland and Sweden. Acta Psychiatrica Scandinavica, 131(4), 297-306. https://doi.org/10.1111/acps.12330

Wilsnack, R. W., Wilsnack, S. C., Kristjanson, A. F., Vogeltanz-Holm, N. D., \& Gmel, G. (2009). Gender and alcohol consumption: patterns from the multinational genacis project. Addiction, 104(9), 1487-1500. https://doi.org/10.1111/j.1360-0443.2009.02696.x.GENDER

Wootton, R. E., Greenstone, H. S. R., Abdellaoui, A., Denys, D., Verweij, K. J. H., Munafò, M. R., \& Treur, J. L. (2021). Bidirectional effects between loneliness, smoking and alcohol use evidence from a Mendelian randomization study. Addiction, 116(2), 400-406. 
https://doi.org/10.1111/add.15142

Yang, Y. C., Mcclintock, M. K., Kozloski, M., \& Li, T. (2013). Social Isolation and Adult Mortality: The Role of Chronic Inflammation and Sex Differences. Journal of Health and Social Behavior, 54(2), 183-203. https://doi.org/10.1177/0022146513485244

Zhao, J., Stockwell, T., Roemer, A., Naimi, T., \& Chikritzhs, T. (2017). Alcohol consumption and mortality from coronary heart disease: an updated meta-analysis of cohort studies. Journal of studies on alcohol and drugs, 78(3), 375-386.

https://doi.org/10.15288/jsad.2017.78.375 
Figure 1. Indirect effect analyses with overall sample.

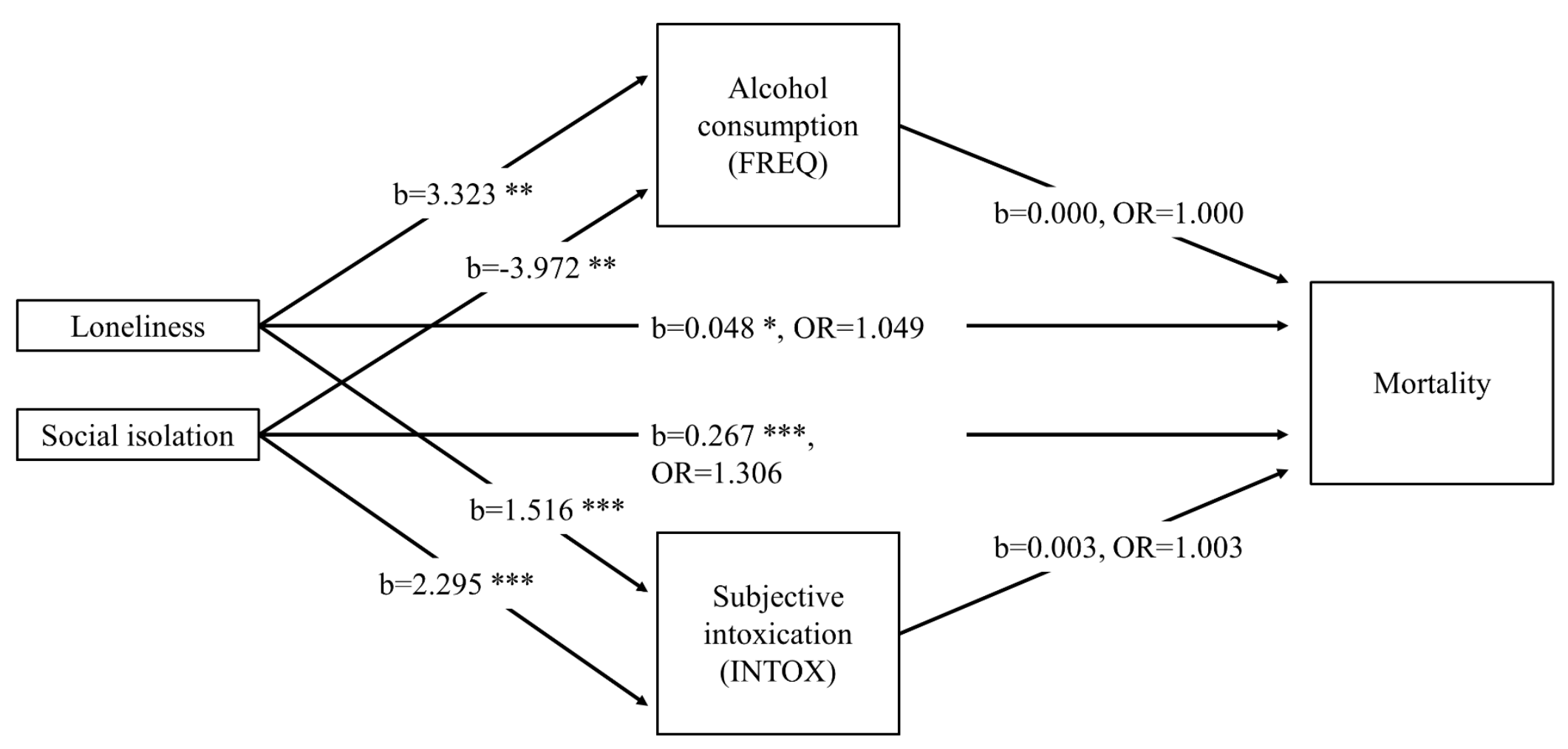


Table 1. Descriptive statistics of study variables in different groups

\begin{tabular}{|c|c|c|c|c|c|c|}
\hline & $\mathbf{N}$ & Loneliness & Social isolation & FREQ & INTOX & Number of deaths \\
\hline All data & 8650 & $2.06(\mathrm{SD}=0.92)$ & $2.40(\mathrm{SD}=0.77)$ & $56.94(\mathrm{SD}=79.05)$ & $7.47(\mathrm{SD}=20.49)$ & $1932(22.2 \%)$ \\
\hline Men under $40 \mathrm{y}$ & 1746 & $2.02(\mathrm{SD}=0.84)$ & $2.46(\mathrm{SD}=0.76)$ & $67.93(\mathrm{SD}=74.38)$ & $13.82(\mathrm{SD}=23.71)$ & $86(4.9 \%)$ \\
\hline Men 40-65y & 2103 & $2.00(\mathrm{SD}=0.93)$ & $2.28(\mathrm{SD}=0.76)$ & $83.37(\mathrm{SD}=98.69)$ & $11.38(\mathrm{SD}=27.06)$ & $573(27.2 \%)$ \\
\hline Men over $65 y$ & 441 & $1.90(\mathrm{SD}=1.04)$ & $2.78(\mathrm{SD}=0.73)$ & $67.21(\mathrm{SD}=106.62)$ & $4.23(\mathrm{SD}=17.25)$ & $393(89.1)$ \\
\hline Women under $40 \mathrm{y}$ & 1761 & $2.16(\mathrm{SD}=0.86)$ & $2.29(\mathrm{SD}=0.70)$ & $37.39(\mathrm{SD}=46.41)$ & $5.10(\mathrm{SD}=13.15)$ & $30(1.7 \%)$ \\
\hline Women $40-65 y$ & 1970 & $2.07(\mathrm{SD}=0.94)$ & $2.26(\mathrm{SD}=0.69)$ & $45.08(\mathrm{SD}=69.04)$ & $2.86(\mathrm{SD}=15.66)$ & $324(16.4 \%)$ \\
\hline Women over $65 y$ & 629 & $2.17(\mathrm{SD}=1.10)$ & $3.16(\mathrm{SD}=0.71)$ & $22.58(\mathrm{SD}=60.73)$ & $0.14(\mathrm{SD}=1.47)$ & $526(83.6 \%)$ \\
\hline
\end{tabular}

Note. The table presents means and standard deviation (DV) for loneliness, social isolation, frequency of overall alcohol consumption

(FREQ) and subjective intoxication frequency (INTOX). In addition, the number and the percentage of deaths in the follow-up period in different groups is presented. 
Table 2. Correlations between main study variables in different groups

\begin{tabular}{|c|c|c|c|c|c|c|c|c|c|c|c|c|c|c|c|c|c|c|c|c|c|}
\hline & \multicolumn{7}{|c|}{ Loneliness } & \multicolumn{7}{|c|}{ Social isolation } & \multicolumn{7}{|c|}{ FREQ } \\
\hline & All & 1 & 2 & 3 & 4 & 5 & 6 & All & 1 & 2 & 3 & 4 & 5 & 6 & All & 1 & 2 & 3 & 4 & 5 & 6 \\
\hline Social isolation & .20 & .21 & .20 & .31 & .21 & .20 & .23 & & & & & & & & & & & & & & \\
\hline FREQ & .02 & .04 & .04 & .02 & .04 & .02 & .06 & -.10 & -.14 & -.05 & -.12 & -.06 & -.10 & -.05 & & & & & & & \\
\hline INTOX & .08 & .07 & .14 & .13 & .09 & .06 & .01 & .06 & .15 & .08 & .02 & .15 & .03 & .01 & .34 & .39 & .31 & .27 & .39 & .28 & .15 \\
\hline
\end{tabular}

Note. 1 = Men under 40y; 2 = Men 40-65y; $3=$ Men over 65y; 4 = Women under 40y; $5=$ Women 40-65y; 6 = Women over 65y.

Bolded correlations are statistically significant. 
Table 3. Direct effects of the path model

\begin{tabular}{|c|c|c|c|c|}
\hline \multirow{9}{*}{ Loneliness } & & FREQ & INTOX & Mortality \\
\hline & All & $3.323[1.445-5.200] * *$ & $1.516[0.915-2.116] * * *$ & $0.048[0.003-0.094] *, \mathrm{OR}=1.049$ \\
\hline & Men under 40y & $2.214[-2.273-6.700]$ & $0.705[-0.855-2.266]$ & $-0.062[-0.283-0.159], \mathrm{OR}=0.940$ \\
\hline & Men 40-65y & $4.642[-0.230-9.514]$ & $3.498[1.788-5.207] * * *$ & $-0.011[-0.107-0.085], \mathrm{OR}=0.989$ \\
\hline & Men over $65 y$ & $6.722[-3.448-16.892]$ & $2.642[-0.253-5.537]$ & $0.063[-0.034-0.160], \mathrm{OR}=1.065$ \\
\hline & Women under 40y & $3.369[0.691-6.046] *$ & $0.889[0.092-1.686] *$ & $0.429[0.009-0.850] *, \mathrm{OR}=1.536$ \\
\hline & Women $40-65 y$ & $1.809[-1.610-5.228]$ & $0.873[-0.216-1.961]$ & $0.116[0.001-0.231], * \mathrm{OR}=1.223$ \\
\hline & Women over $65 y$ & $3.854[-0.551-8.260]$ & $0.005[-0.056-0.067]$ & $0.063[-0.010-0.137], \mathrm{OR}=1.065$ \\
\hline & Difference test & $\mathrm{p}=.887$ & $\mathrm{p}<.001$ & $\mathrm{p}=.214$ \\
\hline \multirow{8}{*}{$\begin{array}{l}\text { Social } \\
\text { isolation }\end{array}$} & All & $-3.972[-6.516--1.427] * *$ & $2.295[1.486-3.104] * * *$ & $0.267[0.200-0.333] * * *, \mathrm{OR}=1.306$ \\
\hline & Men under 40y & $-4.135[-10.195-1.924]$ & $5.217[3.208-7.226] * * *$ & $0.242[-0.104-0.587], \mathrm{OR}=1.274$ \\
\hline & Men 40-65y & $-4.099[-9.802-1.603]$ & $1.988[0.181-3.795] *$ & $0.336[0.223-0.450] * * *, \mathrm{OR}=1.400$ \\
\hline & Men over $65 y$ & $-16.704[-31.401--2.008] *$ & $0.464[-1.101-2.030]$ & $0.122[-0.044-0.287], \mathrm{OR}=1.130$ \\
\hline & Women under 40y & $0.339[-3.627-4.305]$ & $2.560[0.330-4.790] *$ & $0.094[-0.402-0.590], \mathrm{OR}=1.099$ \\
\hline & Women $40-65 y$ & $-4.567[-9.078--0.056] *$ & $0.814[-0.425-2.053]$ & $0.282[0.120-0.444] * *, \mathrm{OR}=1.326$ \\
\hline & Women over $65 y$ & $-2.225[-9.973-5.523]$ & $0.079[-0.002-0.161]$ & $0.265[0.142-0.387] * * *, \mathrm{OR}=1.303$ \\
\hline & Difference test & $\mathrm{p}=.233$ & $\mathrm{p}<.001$ & $\mathrm{p}=.427$ \\
\hline \multirow[t]{8}{*}{ FREQ } & All & & & $0.000[0.000-0.001], \mathrm{OR}=1.000$ \\
\hline & Men under 40y & & & $0.001[-0.002-0.004], \mathrm{OR}=1.001$ \\
\hline & Men 40-65y & & & $0.000[-0.001-0.001], \mathrm{OR}=1.000$ \\
\hline & Men over $65 y$ & & & $0.000[-0.001-0.001], \mathrm{OR}=1.000$ \\
\hline & Women under 40y & & & $0.000[-0.007-0.008], \mathrm{OR}=1.000$ \\
\hline & Women $40-65 y$ & & & $0.000[-0.002-0.002], \mathrm{OR}=1.000$ \\
\hline & Women over $65 y$ & & & $0.000[-0.002-0.002], \mathrm{OR}=1.000$ \\
\hline & Difference test & & & $\mathrm{p}=.995$ \\
\hline \multirow[t]{8}{*}{ INTOX } & All & & & $0.003[0.002-0.005] * * *, \mathrm{OR}=1.003$ \\
\hline & Men under $40 \mathrm{y}$ & & & $0.004[-0.001-0.009], \mathrm{OR}=1.004$ \\
\hline & Men 40-65y & & & $0.004[0.002-0.006] * * *, \mathrm{OR}=1.004$ \\
\hline & Men over $65 y$ & & & $0.001[-0.003-0.005], \mathrm{OR}=1.001$ \\
\hline & Women under 40y & & & $0.011[0.002-0.019] *, \mathrm{OR}=1.011$ \\
\hline & Women $40-65 y$ & & & $0.001[-0.004-0.006], \mathrm{OR}=1.001$ \\
\hline & Women over $65 y$ & & & $-0.033[-0.082-0.017], \mathrm{OR}=0.968$ \\
\hline & Difference test & & & $\mathrm{p}=.166$ \\
\hline
\end{tabular}

Note. ${ }^{*} \mathrm{p}<.0 .50, * * \mathrm{p}<.010, * * * \mathrm{p}<.001$. Table presents path coefficients and also odds ratios (OR) for mortality. 
Table 4. Indirect and total effects of loneliness and social isolation on mortality

\begin{tabular}{|c|c|c|c|c|c|c|}
\hline & \multicolumn{3}{|c|}{ Loneliness $\rightarrow$ Mortality } & \multicolumn{3}{|c|}{ Social isolation $\rightarrow$ Mortality } \\
\hline & $\begin{array}{l}\text { Indirect effect via } \\
\text { FREQ }\end{array}$ & $\begin{array}{l}\text { Indirect effect via } \\
\text { INTOX }\end{array}$ & Total effect & $\begin{array}{l}\text { Indirect effect via } \\
\text { FREQ }\end{array}$ & $\begin{array}{l}\text { Indirect effect via } \\
\text { INTOX }\end{array}$ & Total effect \\
\hline All & $1.000[1.000-1.000]$ & $1.005[1.001-1.008]^{\mathrm{a}}$ & $1.054[1.007-1.103]^{\mathrm{a}}$ & $1.000[1.000-1.000]$ & $1.007[1.002-1.013]^{\mathrm{a}}$ & $1.315[1.230-1.406]^{\mathrm{a}}$ \\
\hline Men under 40y & $1.002[0.996-1.012]$ & $1.003[0.996-1.014]$ & $0.945[0.756-1.179]$ & $0.996[0.981-1.005]$ & $1.021[0.990-1.057]$ & $1.296[0.916-1.832]$ \\
\hline Men 40-65y & $1.000[1.000-1.000]$ & $1.014[1.005-1.025]^{\mathrm{a}}$ & $1.003[0.911-1.105]$ & $1.000[1.000-1.000]$ & $1.008[1.001-1.018]^{\mathrm{a}}$ & $1.411[1.258-1.581]^{\mathrm{a}}$ \\
\hline Men over $65 y$ & $1.000[1.000-1.000]$ & $1.003[0.991-1.017]$ & 1.068 [0.968-1.179] & $1.000[1.000-1.000]$ & $1.000[0.997-1.005]$ & $1.130[0.957-1.335]$ \\
\hline Women under $40 \mathrm{y}$ & $1.000[0.970-1.031]$ & $1.010[1.000-1.024]^{\mathrm{a}}$ & $1.551[1.016-2.363]^{\mathrm{a}}$ & $1.000[0.982-1.018]$ & $1.029[1.002-1.069]^{\mathrm{a}}$ & $1.130[0.688-1.858]$ \\
\hline Women $40-65 y$ & $1.000[0.995-1.005]$ & $1.001[0.997-1.006]$ & $1.124[1.001-1.262]^{\mathrm{a}}$ & $1.000[0.989-1.011]$ & $1.001[0.997-1.006]$ & $1.327[1.130-1.559]^{\mathrm{a}}$ \\
\hline Women over $65 y$ & $1.000[0.991-1.010]$ & $1.000[0.997-1.002]$ & $1.065[0.990-1.145]$ & $1.000[0.990-1.010]$ & $0.997[0.991-1.001]$ & $1.300[1.151-1.468]^{\mathrm{a}}$ \\
\hline
\end{tabular}

Note. Table presents odds ratios. ${ }^{\text {a }} 95 \%$ confidence interval does not include one. 